\title{
Hammerstein Model Based RLS Algorithm for Modeling the Intelligent Pneumatic Actuator (IPA) System
}

\author{
Siti Fatimah Sulaiman ${ }^{1,2}$, M.F. Rahmat ${ }^{1 \#}$, A.A.M. Faudzi ${ }^{1,3}$, Khairuddin Osman ${ }^{2}$, N.H. Sunar ${ }^{1}$ and \\ Sy Najib Sy Salim ${ }^{4}$ \\ ${ }^{I}$ Department of Control and Mechatronics Engineering, Universiti Teknologi Malaysia, 81310 UTM Johor Bahru, Johor Darul Takzim, \\ Malaysia \\ E-mail: sitifatimahsulaiman@utem.edu.my, ${ }^{\sharp}$ fuaad@fke.utm.my,noorhazirah2809@yahoo.com \\ ${ }^{2}$ Department of Industrial Electronics, Universiti Teknikal Malaysia Melaka, Hang Tuah Jaya, 76100 Durian Tunggal, Melaka, Malaysia \\ E-mail: khairuddin.osman@utem.edu.my \\ ${ }^{3}$ Centre for Artificial Intelligence and Robotics, Universiti Teknologi Malaysia, 81310 UTM Johor Bahru, Johor Darul Takzim, Malaysia \\ ${ }^{4}$ Department of Electrical Engineering Technology, Universiti Teknikal Malaysia Melaka, Hang Tuah Jaya, 76100 Durian Tunggal, \\ Melaka, Malaysia \\ E-mail: syednajib@utem.edu.my
}

\begin{abstract}
An Intelligent Pneumatic Actuator (IPA) system is considered highly nonlinear and subject to nonlinearities which make the precise position control of this actuator is difficult to achieve. Thus, it is appropriate to model the system using nonlinear approach because the linear model sometimes not sufficient enough to represent the nonlinearity of the system in the real process. This study presents a new modeling of an IPA system using Hammerstein model based Recursive Least Square (RLS) algorithm. The Hammerstein model is one of the blocks structured nonlinear models often used to model a nonlinear system and it consists of a static nonlinear block followed by a linear block of dynamic element. In this study, the static nonlinear block was represented by a deadzone of the pneumatic valve, while the linear block was represented by a dynamic element of IPA system. A RLS has been employed as the main algorithm in order to estimate the parameters of the Hammerstein model. The validity of the proposed model has been verified by conducting a real-time experiment. All of the criteria as outlined in the system identification's procedures were successfully complied by the proposed Hammerstein model as it managed to provide a stable system, higher best fit, lower loss function and lower final prediction error than a linear model developed before. The performance of the proposed Hammerstein model in controlling the IPA's positioning system is also considered good. Thus, this new developed Hammerstein model is sufficient enough to represents the IPA system utilized in this study.
\end{abstract}

Keywords — pneumatic; system identification; hammerstein; RLS; valve deadzone

\section{INTRODUCTION}

Pneumatic system is one type of actuator that is commonly used in industry other than hydraulic, electrical, thermal, and magnetic. This type of actuator will only operate when sufficient compressed air supplied to it. However, like most real systems, pneumatic actuator system is a system that is not linear. This is due the issues such as valve deadzone, air leakage, friction effect, and etc. that are presented in the system [1],[2]. Thus, the modeling process of pneumatic system becomes complicated because of these issues. Factors that make the system not linear should be taken into account during the modeling process in order to represent the overall system precisely. Over the past decade, many studies have been done to model the entire pneumatic system. Review of previously studies summarized that there are two approaches commonly used by researchers to model the pneumatic system (either linear or non-linear); a theoretical (first principle) and experimental approach [3][11].

This study will focus on the second approach for modeling the pneumatic system utilized. A highly practical 
alternative and easily deal with the complex system or process [12],[13] are the reasons why the latter approach is selected to be employed.

In system identification, there are a few structure of model that can be utilized to represent the system [14]. Recently, researchers have shown an increased interest of using blockoriented or block-structured nonlinear model in modeling the system. A block-oriented nonlinear model is a model that consist a series of blocks that represent both memoryless nonlinearity and linear dynamic of the system based on input and output measurement of the system [15]. Extensive review revealed that a Hammerstein model is among the block-oriented nonlinear model of choice for modeling any system [16]-[20] and studies in [21]-[23] proved that a Hammerstein model can also be used to model the pneumatic actuator system.

Basically, a Hammerstein model consists of a static nonlinear block and linear dynamic block in cascade. In this study, the static nonlinear block of Hammerstein model will be represented by a deadzone of the pneumatic valve, while the linear block will be represented by a dynamic element of the system. Previously studies on modeling the nonlinear system using Hammerstein model also reported that a recursive and iterative algorithm is often a choice to be used as a parameter estimator for the model [16]-[18],[20]. Iterative algorithm is often used in off-line estimation, while recursive algorithm is often used in on-line estimation [20]. Based on the reviews, this study proposes a Hammerstein model as a new model for a pneumatic system utilized in this study and Recursive Least Square (RLS) algorithm as the parameter estimator for the developed Hammerstein model.

This rest of the paper is organized as follows: The IPA system operations and its components are described in Section 2. The methodology and procedures in modeling the IPA system using system identification approach, and the simulation and experimental results based on the new developed model are discussed in Section 3, and the overall findings are concluded in Section 4.

\section{MATERIAL AND METHOD}

The pneumatic actuator system, namely the Intelligent Pneumatic Actuator (IPA) system utilized in this study is classified as the linear double-acting cylinder type with $0.01 \mathrm{~mm}$ position accuracy. The system is equipped with five main components (as illustrated in Fig. 1); the pressure sensor, optical sensor, laser stripe rod, on/off valves, and Programmable System on Chip (PSoC) control board. Each of these components has their own function in ensuring the IPA system works well, and each of them is interconnected with each other.

In this study, two valves have been used for controlling the IPA positioning system. Both valves were used to control the inlet and outlet air of the cylinder, and a Pulse Width Modulator (PWM) signal was used to drive these valves. The PWM signal will behave according to the current pressure readings given by the pressure sensor and current position readings given by the optical sensor. While the PSoC control board will act as the "brain" to control the whole operation of IPA system. The system is said to be socalled "intelligent" since it integrates actuator, microprocessor and sensors together in one system [24].

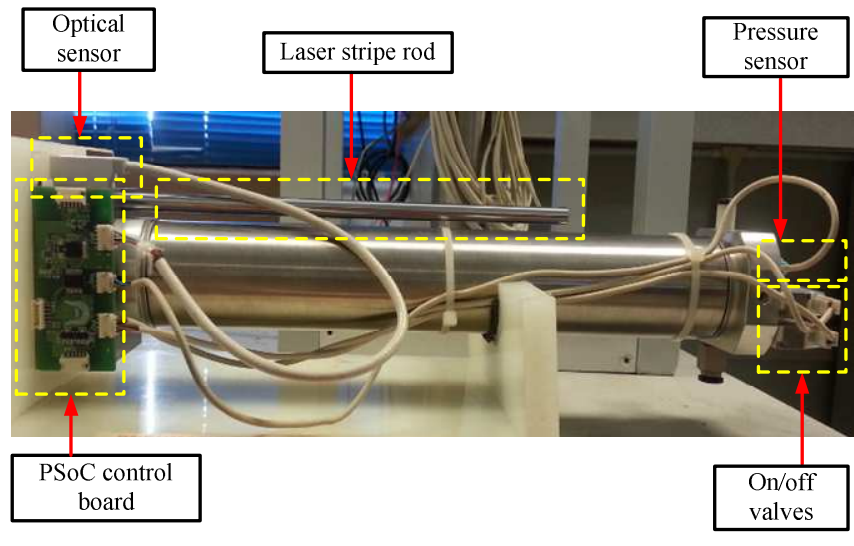

Fig. 1 The IPA system

System identification has been employed as a modeling approach to represent the IPA system utilized in this study. System identification concept can be as simple as a "blind" approach using black-box model concept to obtain a linear and nonlinear model of the system/framework in view of measured exploratory information. Generally, modeling of the system using system identification approach will go through these four accompanying procedures:

\section{A. Experimental Design and Data Collection}

For the technique and procedures utilized for designing the experiment, the previous research in [25]-[28] were referred. The components used during the process of collecting data have been listed in Table 1 and the IPA system's specifications have been described in Table 2 .

TABLE I

LIST OF COMPONENTS USED FOR DATA COLLECTION

\begin{tabular}{|c|c|c|c|}
\hline Component & Model & Quantity & Remarks \\
\hline $\begin{array}{c}\text { Actuator } \\
\text { (Double Acting) }\end{array}$ & $\begin{array}{c}\text { KOGANEI-HA: } \\
\text { Twinport } \\
\text { Cylinders }\end{array}$ & 1 & \\
\hline Optical Sensor & AEDR-8300 & 1 & $\begin{array}{c}\text { Counter } \\
\text { Input }\end{array}$ \\
\hline Pressure Sensor & $\begin{array}{c}\text { KOGANEI: } \\
\text { PSU-EM-S }\end{array}$ & 1 & $\begin{array}{c}\text { Analog } \\
\text { Input }\end{array}$ \\
\hline Valves & KOGANEI: & 2 & $\begin{array}{c}\text { Analog } \\
\text { Output } \\
\text { (On/Off) }\end{array}$ \\
$\begin{array}{c}\text { EB10ES1-PS- } \\
\text { 6W }\end{array}$ & & \\
\hline
\end{tabular}

TABLE II

THE IPA SYSTEM'S SPECIFICATIONS

\begin{tabular}{|c|c|c|}
\hline Parameters & Value & Remarks \\
\hline $\begin{array}{c}\text { Actuator } \\
\text { Diameter }\end{array}$ & $40 \mathrm{~mm}$ & \\
\hline Rod Diameter & $16 \mathrm{~mm}$ & \\
\hline Rod Stroke & $200 \mathrm{~mm}$ & \\
\hline $\begin{array}{c}\text { Maximum Force } \\
\text { (At 0.6MPa) }\end{array}$ & $120 \mathrm{~N}$ & ISO 6358 \\
\hline Ambient Force & $0 \mathrm{~N}$ & ISO 6358 \\
\hline $\begin{array}{c}\text { Specific Heat } \\
\text { Ratio }\end{array}$ & 1.4 & \\
\hline Temperature & $294.5 \mathrm{~K}$ & \\
\hline
\end{tabular}

2000 measurements of input and output data with sampling time $\left(T_{s}\right) 0.01 \mathrm{~s}$ were collected from real-time 
experiment. The data contains 2000 data points of signal applied to the valves (input data) and 2000 measurements of the position signal (output data). The signal applied to the valves is a continuous step signal with amplitude \pm 255 , and specially designed for the on/off valves of IPA system. While the output signals represent the position of IPA's stroke in $\mathrm{mm}$. The plot of input and output data are shown in Fig. 2.

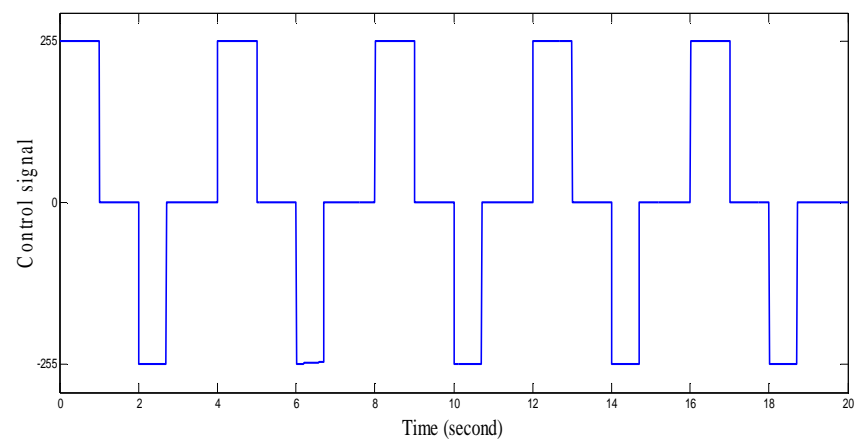

(a)

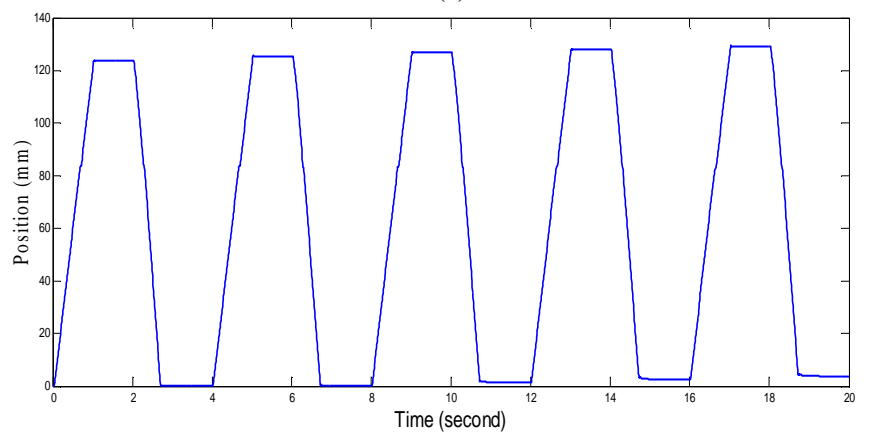

(b)

Fig. 2 The plot of collected data from real-time experiment: (a) input, (b) output

\section{B. Model Structure Selection}

In this study, the Hammerstein model or so-called a block-oriented or block-structured model was used in order to represent the real IPA system. The basic structure of a Hammerstein model consists of a static nonlinear block and linear dynamic block in cascade, as illustrated in Fig. 3. In this study, the static nonlinear block was represented by a nonlinear deadzone of the IPA valve, while the linear block was represented by a linear dynamic of IPA system itself. $u(k), x(k), \ominus(k)$ and $y(k)$ represents the input, internal variable, noise and output signals, respectively.

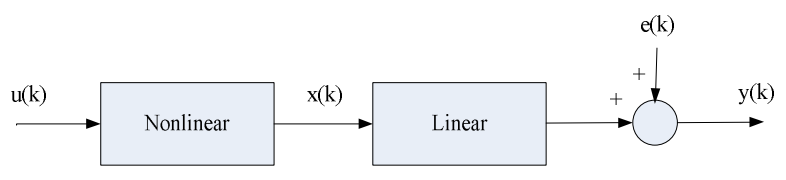

Fig. 3 The basic structure of a Hammerstein model

As previously described, a valve deadzone of IPA system will be considered as a nonlinearity block of the Hammerstein model proposed in this study. A nonlinear valve deadzone in IPA system can be described as a situation where the cylinder stroke does not give any response (extend or retract) for a given range of input voltage to the valve, until the input voltage reaches a particular value. The analytical expression of the valve deadzone for IPA system utilized in this study was referred from [21],[29] and can be expressed as Equation (1), while its graphical representation can be illustrated as in Fig. 4.

$$
x(k)=\left\{\begin{array}{cc}
m_{l}\left[u(k)-b_{l}\right] & ; u(k) \leq b_{l} \\
0 & ; b_{l}<w(k)<b_{r} \\
m_{r}\left[u(k)-b_{r}\right] & ; u(k) \geq b_{r}
\end{array}\right.
$$

where $b_{l}$ and $b_{\gamma}$ are the deadzone points, $m_{\eta}$ and $m_{r}$ the corresponding segment slopes, $u(k)$ and $x(k)$ the input and output signals of the nonlinear valve deadzone.

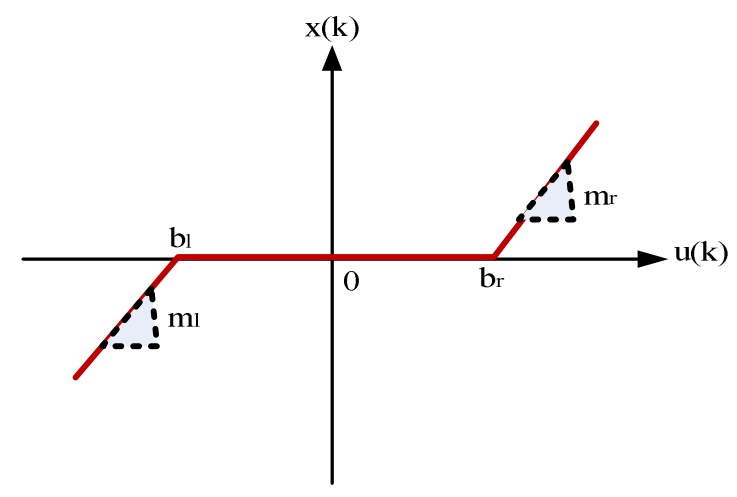

Fig. 4 A graphical representation of the valve deadzone for IPA system

In this study, an auxiliary function called as switching function expressed in Equation (2) and Equation (3) was introduced in order to write the behavior of the deadzone in Equation (1) so that it is linear in parameter [21].

$$
\begin{aligned}
& x_{l}(k)= \begin{cases}1 & ; u(k) \leq b_{l} \\
0 & ; u(k) \geq b_{l}\end{cases} \\
& x_{Y}(k)= \begin{cases}1 & ; u(k) \geq b_{r} \\
0 & ; u(k)<b_{r}\end{cases}
\end{aligned}
$$

Thus, the deadzone equation (Equation (1)) can be represented as Equation (4).

$$
\begin{gathered}
x(k)= \\
x_{l}(k)\left[m_{\eta}\left[u(k)-b_{l}\right]\right]+x_{\gamma}(k)\left[m_{\gamma}\left[u(k)-b_{\gamma}\right]\right]
\end{gathered}
$$

In this study, the linear block of the Hammerstein model (illustrated in Fig. 3) is represented by a linear dynamic of IPA system and a third order Auto-Regressive with Exogenous input (ARX) has been considered as a model structure in order to describe the system. Thus, the linear part of the Hammerstein model represented in a discretetime ARX model structure can be written as Equation (5).

$$
y(k)=z^{-d} \frac{B(z)}{A(z)} x(k)+\theta(k)
$$

where, 
$A(z)=1+a_{1} z^{-1}+a_{2} z^{-2}+\cdots+a_{n z} z^{-n_{n}}$, and

$B(z)=b_{0}+b_{1} z^{-1}+b_{2} z^{-2}+\cdots+b_{n_{b}} z^{-n_{b}}$

where $n_{a}$ is the number of system poles, $n_{\bar{b}}$ the number of system zeros, $d$ the pure delay system, and $z^{-1}$ is the shift operator. So, $x(k) z^{-d}=x(k-d$.

Equation (5) can also be written in the form of summations as in Equation (6).

$$
\sum_{i=0}^{n_{b}} b_{i} x(k-a-i)-\sum_{j=1}^{n_{n}} a_{j} y(k-j)+\sum_{j=1}^{n_{n}} a_{j} \theta(k-j)+e(k)
$$

Substituting Equation (4) into Equation (6) gives Equation (7).

$$
\begin{gathered}
y(k)= \\
\sum_{i=0}^{n_{b}} b_{i}\left\{\begin{array}{c}
x_{l}(k-d-i) m_{l}[u(k-d-i)] \\
+x_{r}(k-d-i) m_{r}\left[u(k-d-i)-b_{r}\right]
\end{array}\right) \\
-\sum_{j=1}^{n_{n}} a_{j} y(k-j)+\sum_{j=1}^{n_{n}} a_{j} \in(k-j)+e(k)
\end{gathered}
$$

Then, the complete Hammerstein model for IPA system written in regression equation can be expressed as Equation (8).

$$
y(k)=p^{2}(k) \hat{\theta}+\epsilon(k)
$$

where the regressor vector,

$$
\varphi^{T}(k)=\left[\begin{array}{c}
x_{l}(k-d) u(k-d),-x_{l}(k-d)_{2} \\
x_{r}(k-d) u(k-d),-x_{r}(k-d) \\
-y(k-1), \cdots,-y\left(k-n_{a}\right) \\
x(k-d-1), \cdots, x\left(k-d-n_{b}\right)
\end{array}\right]
$$

and the parameter vector,

$\boldsymbol{\theta}=\left[\begin{array}{c}\left.b_{0} m_{l}, b_{0} m_{l} b_{l}, b_{0} m_{r}, b_{0} m_{r} b_{r}\right] \\ a_{1}, \cdots, a_{n_{a}}, b_{1}, \cdots, b_{n_{b}}\end{array}\right]^{T}$

\section{Parameter Estimation}

In parameter estimation procedure, the mathematical model estimated by a particular estimation technique is measured in term of how accurate the model prediction output compared to the actual or measured output. In this study, the Recursive Least Square (RLS) algorithm will be used to determine the coefficients or parameters of the Hammerstein model. The RLS algorithm has been considered to be utilized in this study since it can provide faster convergence speed/rate and control performance, and it also does not exhibit the eigenvalues spread problem. The RLS algorithm employed in order to estimate the regression equation (Equation (8)) are listed as in Equation (9) to Equation (12).

$$
\theta(k)=\theta(k-1)+L(k) E(k)
$$

where,

$$
\begin{gathered}
L(k)=\frac{\rho(k-1) \varphi(k)}{\rho+\phi^{T}(k)(k-1) \varphi(k)} \\
\varepsilon(k)=y(k)-\rho^{2}(k) \theta(k-1) \\
P(k)=\frac{1}{\rho}\left[P(k-1)-L(k) \varphi^{2}(k) P(k-1)\right]
\end{gathered}
$$

where $L$ is the least squares weighting factor, $P$ the matrix that is proportional to the variance of the previous estimates, $\boldsymbol{\rho}$ the forgetting factor, $\boldsymbol{z}$ the current estimation error, $\vec{\theta}$ the parameter vector, $\phi$ the information vector, and $y$ the output vector.

\section{Model Validation}

In model validation, the validity between the measured and developed Hammerstein model under a validation requirement was checked in order verify that the identified Hammerstein model represents IPA system adequately. In this study, the Akaike's Model Validity Criterion was employed and the model was validated based on poles location, best fit, loss function and final prediction error. Observing the location of the poles of the system is highly necessary since it provides the information about the system's stability. The developed Hammerstein model is said to be stable if it manage to keep the location of the poles of the linear model in the range of -1 to 1 (unit circle). Besides, the developed Hammerstein model is also considered acceptable if it manage to provide the model with higher best fit, lower loss function and lower final prediction error. The equation used to determine the percentage of best fit, loss function and final prediction error can be represented as in Equation (13), Equation (14) and Equation (15), respectively.

$$
\operatorname{Bestfit}(\%)=\left(1-\frac{\mathrm{d} y-y \mathrm{l}}{\mathrm{b} y-y \mathrm{l}}\right) \times 100
$$

where $y$ is the measured output, $\hat{y}$ the estimated output and $\bar{y}$ the mean value of the measured output.

$$
V(\hat{\theta})=\frac{1}{N} \sum_{k=1}^{N} \frac{1}{2} z_{k}^{2}
$$

where,

$z_{h}(\hat{\theta})=y_{k}-\varphi^{T}{ }_{k}(\hat{\theta})$

where $N$ is the number of data points and $\boldsymbol{\varepsilon}$ the estimation error.

$$
F P E=\frac{N+p}{N-p} V(\theta)
$$

where $p$ is the number of parameters in the model, $N$ the number of data points and $V$ the loss function. 


\section{RESULTS AND DISCUSSION}

This study presents a new modeling for Intelligent Pneumatic Actuator (IPA) system using nonlinear system identification approach. The aim of this study is to model the entire IPA system using Hammerstein model and estimate all the parameters of the model using a Recursive Least Square (RLS) algorithm. Table 3 shows the estimated parameter values for Hammerstein model obtained using RLS algorithm.

TABLE III

HAMMERSTEIN MODEL PARAMETER VALUES

\begin{tabular}{|c|c|c|c|}
\hline Block & Parameter & $\begin{array}{c}\text { Estimated } \\
\text { Value }\end{array}$ & Actual Value \\
\hline \multirow{4}{*}{$\begin{array}{c}\text { Nonlinear } \\
\text { (Valve } \\
\text { Deadzone) }\end{array}$} & $b_{y}$ & 1.4120 & 1.4100 \\
\cline { 2 - 4 } & $b_{l}$ & -1.5010 & -1.5000 \\
\cline { 2 - 4 } & $m_{r}$ & 2.3810 & 2.3800 \\
\cline { 2 - 4 } & $m_{l}$ & 3.4710 & 3.4600 \\
\cline { 2 - 4 } $\begin{array}{c}\text { Linear } \\
\text { (Dynamic of } \\
\text { IPA System) }\end{array}$ & $a_{1}$ & -1.8200 & -1.8690 \\
\cline { 2 - 4 } & $a_{n}$ & 1.0010 & 0.9976 \\
\cline { 2 - 4 } & $a_{\mathfrak{a}}$ & -0.1808 & -0.1284 \\
\hline & $b_{1}$ & $7.4980 \times 10^{-4}$ & $15.6700 \times 10^{-4}$ \\
\hline
\end{tabular}

To confirm the acceptance of the developed Hammerstein model, the model has been validated according poles location of a linear ARX model, best fit, loss function and final prediction error. The estimated linear ARX model using RLS algorithm have resulted the entire poles lie inside a unit circle $(0.9994,0.4103 \pm 0.1121 \mathrm{i})$, thus proved that the linear ARX model is stable. Meanwhile, the plot in Fig. 5 illustrates the output fittings between the developed Hammerstein model and previous linear ARX model (the model used in previous research) against the measured output (position).

It can be seen that both models produced a good fitting, however, Hammerstein model has managed to give a better fitting than linear ARX model. This indicates that the developed Hammerstein model successfully represents the real IPA system utilized in this study and the addition of nonlinear block (nonlinear valve deadzone) in the model very helpful to get a better model.

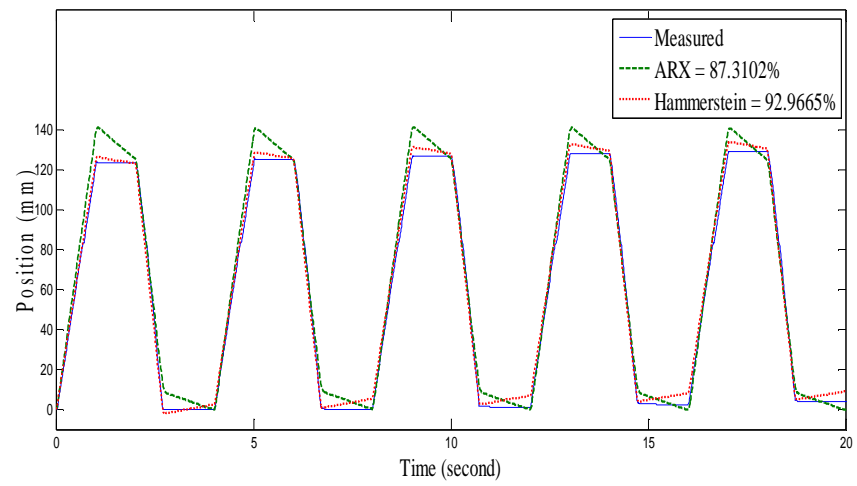

Fig. 5 The output fittings for a developed Hammerstein model and previous linear model
Apart from the $5.6563 \%$ improvement on fitting, the developed Hammerstein model also managed to reduce loss function and final prediction error by $3.5490 \times 10^{-3}$ and $3.5439 \times 10^{-3}$, respectively. Summary of the best fit, loss function and final prediction error for both models are tabulated in Table 4.

TABLE IV

MODEL VALIDATION VALUES

\begin{tabular}{|c|c|c|}
\hline \multirow{2}{*}{ Criteria } & \multicolumn{2}{|c|}{ Model } \\
\cline { 2 - 3 } Best Fit (\%) & Linear ARX & Hammerstein \\
\hline Loss Function & 47.3102 & 92.9665 \\
\hline Final Prediction Error & $4.4000 \times 10^{-3}$ & $0.8510 \times 10^{-3}$ \\
\hline
\end{tabular}

Open-loop and closed-loop test were also conducted in order to test the functional reliability of the estimated Hammerstein model to represent the real IPA system. Fig. 6 show the corresponding responses between simulated Hammerstein model and real-time IPA system for open loop test. As seen in Fig. 6, the simulated Hammerstein model has managed to provide a response that is similar to the real IPA system.

Closed-loop test was also performed on the developed Hammerstein model in order to test its ability to control the IPA positioning system. In this study, a simple ProportionalIntegral (PI) $\left(K_{p}=14\right.$ and $\left.K_{i}=1\right)$ is used as a controller and the corresponding responses when the set-point to be reached is fixed and unfixed were compared. Fig. 7(a) and Fig. 7(b) illustrate the simulated and actual response of the IPA's stroke position for fixed and unfixed set-point, respectively. From both plots, it can be stated that Hammerstein model developed in this study can be used to represent the real IPA system, which the response from the simulation was better than the real-time experiment. This is because the simulation does not take into account other nonlinearity factors such as water leakage, friction, air compressibility, etc. as in the realtime experiment. The performance between developed Hammerstein model (simulated) and real IPA system (experiment) for fixed position were compared and summary of the data obtained are tabulated in Table 5.It can be seen from Table 5 that the experiment has provided a higher value for overshoot, steady-state error, rising time, and settling time than simulation. However, the results obtained from the experiment is still acceptable in this study as the overshoot and steady-state error are $<10 \%$ and $<2 \%$, respectively.

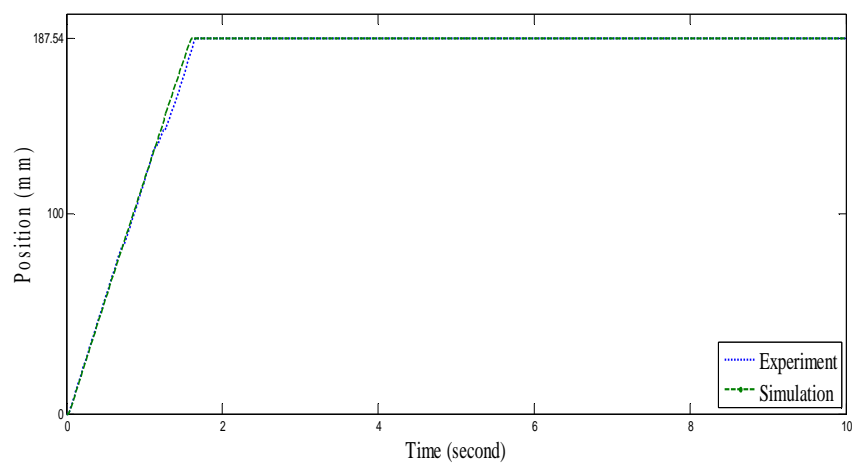

Fig. 6 Open-loop test 


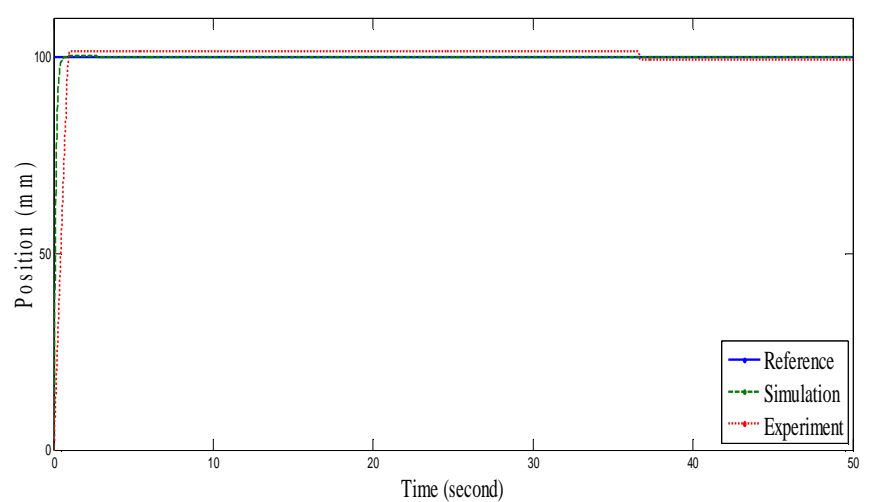

(a)

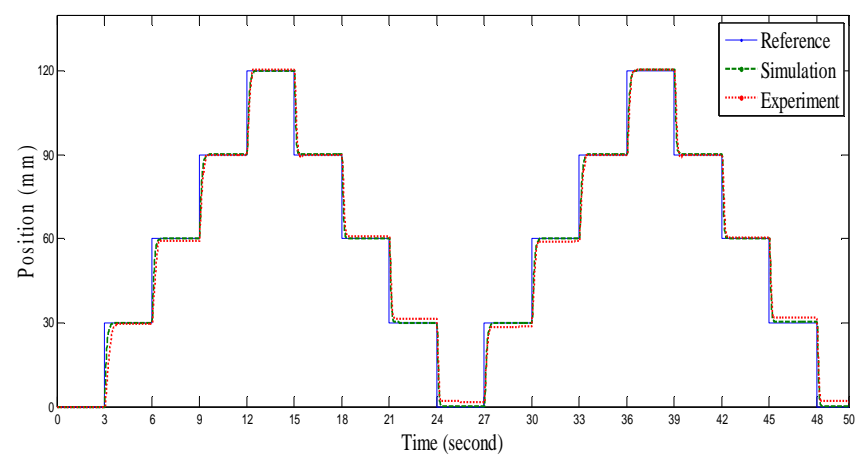

(b)

Fig. 7 Closed-loop test: (a) fixed set-point, (b) unfixed set-point

TABLE V

CLOSED-LOOP PERFORMANCES

\begin{tabular}{|c|c|c|}
\hline \multirow{2}{*}{ Criteria } & \multicolumn{2}{|c|}{ Closed-Loop } \\
\cline { 2 - 3 } & $\begin{array}{c}\text { Hammerstein } \\
\text { (Simulation) }\end{array}$ & $\begin{array}{c}\text { Real IPA } \\
\text { (Experiment) }\end{array}$ \\
\hline $\begin{array}{c}\text { Overshoot }(\boldsymbol{0}) \mathbf{5}) \\
\text { Steady-State Error } \\
\left(\boldsymbol{e}_{s s}\right)\end{array}$ & $0.1173 \mathrm{~mm}$ & $2.1849 \mathrm{~mm}$ \\
\hline Rising Time $\left(\boldsymbol{t}_{\boldsymbol{r}}\right)$ & $0.0037 \mathrm{~mm}$ & $0.6800 \mathrm{~mm}$ \\
\hline Settling Time $\left(\boldsymbol{t}_{\boldsymbol{g}}\right)$ & $0.4194 \mathrm{~s}$ & $36.5939 \mathrm{~s}$ \\
\hline
\end{tabular}

\section{CONCLUSION}

This paper presents a new modeling of Intelligent Pneumatic Actuator (IPA) system using Hammerstein model based a Recursive Least Square (RLS) algorithm. An experimental approach, known as system identification technique was used to develop the model of IPA system used in this study. The nonlinear and linear block for a Hammerstein model was represented by valve deadzone and third-order ARX model for IPA system, respectively. The RLS algorithm was employed to estimate all the parameters for a Hammerstein model. Validation through Akaike's Model Validity Criterion shows that the developed Hammerstein model is acceptable as it managed to provide a higher fitness, lower loss function and lower final prediction error than the linear model developed before. Thus, shows that the model is good enough to represent the real IPA system utilized in this study. Besides that, the developed Hammerstein model also proved to be used as a model for the purpose of controlling the position of IPA system. Future study investigating the suitable controller to improve the transient response of the IPA positioning system, especially in real-time environment will be considered as the next stage of this study.

\section{ACKNOWLEDGMENT}

The authors would like to acknowledge Universiti Teknologi Malaysia (UTM), Universiti Teknikal Malaysia Melaka (UTeM) and Ministry of Higher Education (MOHE) of Malaysia for their support. The great thanks also go to all of the people who contributed in this study.

\section{REFERENCES}

[1] S. N. S. Salim, M. F. Rahmat, A. A. M. Faudzi, N. H. Sunar, Z. H. Ismail, and S. I. Samsudin, "Tracking performance and disturbance rejection of pneumatic actuator system," in IEEE $20139^{\text {th }}$ Asian Control Conference, 2013, p. 1.

[2] R. Ghazali, Y. M. Sam, M. F. Rahmat, A. W. I. M. Hashim, and Zulatman, "Performance comparison between sliding mode control with PID sliding surface and PID controller for an electro-hydraulic positioning system,"International Journal on Advanced Science Engineering Information Technology, vol. 1, pp. 447-452, Jan. 2011.

[3] K. Hamiti, A. Voda-Besancon, and H. Roux-Buisson, "Position control of a pneumatic actuator under the influence of stiction," Control Engineering Practice, vol. 4, pp. 1079-1088, 1996.

[4] J. Wu, M. Goldfarb, and E. Barth, "On the observability of pressure in a pneumatic servo actuator," Journal of Dynamic Systems, Measurement, and Control, vol. 126, pp. 921-924, 2004.

[5] C. R. Burrows and C. R. Webb, "Use of root loci in design of pneumatic servo-motors (pneumatic servomotor synthesis by root loci technique providing direct insight into effects of parameter changes on system response," Control, vol. 10, pp. 423-427, 1966.

[6] I. G. French and C. S. Cox, "Modelling, design and control of a modern electropneumatic actuator," in IEE Proceedings D - Control Theory and Applications, 1990, p. 145.

[7] M. Sorli, L. Gastaldi, E. Codina, and S. de las Heras, "Dynamic analysis of pneumatic actuators," Simulation Practice and Theory, vol. 7, pp. 589-602, 1999.

[8] E. Richer and Y. Hurmuzlu, "A high performance pneumatic force actuator system: part II - nonlinear controller design," Journal of Dynamic Systems, Measurement, and Control, vol. 122, pp. 416-425, 2000.

[9] A. Messina, N. I. Giannoccaro, and A. Gentile, "Experimenting and modelling the dynamics of pneumatic actuators controlled by the pulse width modulation (PWM) technique," Mechatronics, vol. 15, pp. 859-881, 2005.

[10] S. Ning and G. M. Bone, "Development of a nonlinear dynamic model for a servo pneumatic positioning system," in IEEE International Conference in Mechatronics and Automation, 2005, p.43.

[11] G. Carducci, N. I. Giannoccaro, A. Messina, and G. Rollo, "Identification of viscous friction coefficients for a pneumatic system model using optimization methods," Mathematics and Computers in Simulations, vol. 71, pp. 385-394, 2006.

[12] L. Ljung and T. Glad, Modelling of Dynamic Systems, Prentice-Hall, Inc. Upper Saddle River, NJ, USA, 1994.

[13] D. Hanafi, M. S. Suid, M. N. Ribuan, R. Omar, M. N. M. Than, and M. F. Rahmat, "Speed effect to a quarter car ARX model based on system identification," International Journal on Advanced Science Engineering Information Technology, vol. 7, pp. 468-474, 2017.

[14] L. Ljung, System Identification Toolbox ${ }^{T M}$ User's Guide, Mathworks, 2015.

[15] X. P. Xu, F. Dai, F. Wang, and F. C. Qian, "An identification method for a block oriented model," in International Conference on Artificial Intelligence and Industrial Engineering, 2015, p. 425.

[16] J. Vörös, "Parameter identification of Hammerstein system with asymmetric dead-zones," Journal of Electrical Engineering, vol. 55, pp. 46-49, 2004. 
[17] W. Lin, H. Zhang, and P. X. Liu, "A new identification method for Hammerstein model based PSO," in Proceedings of the 2006 IEEE International Conference on Mechatronics and Automation, 2006, p.2184.

[18] K. S. Narendra and P. G. Gallman, "An iterative method or the identification of nonlinear system using a Hammerstein model," IEEE Transactions on Automatic Control, pp. 546-550, 1966.

[19] W. X. Zhao and H. F. Chen, "Recursive identification of Hammerstein system with ARX subsystem," in Proceedings of the $25^{\text {th }}$ Chinese Control Conference, 2006, p. 473.

[20] J. Chen, X. Wang and R. Ding, "Gradient based estimation algorithm for Hammerstein systems with saturation and dead-zones nonlinearities," Applied Mathematical Modelling, vol. 36, 238-243, 2012.

[21] A. C. T. de Cequeira, M. R. B. G. Vale, D. G. V. da Fonseca, F.M.U de Araújo, and A. L. Maitelli, "Estimation and compensation of dead-zone inherent to the actuators of industrial processes," in $7^{\text {th }}$ International Conference on Informatics in Control, Automation and Robotics, 2010, p. 62.

[22] X. Shi and H. T. Zhang, "Modeling of pneumatic muscle actuators based on Hammerstein system," in Proceedings of the $35^{\text {th }}$ Chinese Control Conference, 2016.

[23] N. H. Sunar, M. F. Rahmat, Z. H. Ismail, A. A. M. Faudzi, and S. N S. Salim, "Model identification and controller design for an electropneumatic actuator system with dead zone compensation,"
International Journal on Smart Sensing and Intelligent System, vol. 7, pp. 798-819, 2014.

[24] A. A. M. Faudzi, K. Suzumori and S. Wakimoto, "Development of pneumatic actuated seating system to aid chair design," in IEEE/ASME International Conference on Advanced Intelligent Mechatronics, 2010, p. 1035.

[25] S. F. Sulaiman, M. F. Rahmat, A. A. M. Faudzi, and K. Osman, "Design of unconstrained and constrained model predictive control for pneumatic actuator system: set-point tracking," in 2015 IEEE Conference on Systems, Process and Control, 2015, p.112.

[26] S. F. Sulaiman, M. F. Rahmat, A. A. M. Faudzi, and K. Osman, "Disturbance rejection using model predictive control for pneumatic actuator system," in 2016 IEEE $12^{\text {th }}$ International Colloquium on Signal Processing \& its Applications, 2016, p. 285.

[27] S. F. Sulaiman, M. F. Rahmat, A. A. M. Faudzi, and K. Osman, "Linear and nonlinear ARX model for intelligent pneumatic actuator systems," Jurnal Teknologi, vol. 78, pp. 21-28, 2016.

[28] S. F. Sulaiman, M. F. Rahmat, A. A. M. Faudzi, K. Osman, S. N. S Salim, S. I. Samsudin, and A. R. Azira, "Enhanced position control for pneumatic system by applying constraints in MPC algorithm," International Journal of Electrical and Computer Engineering, vol. 7, pp. 1633-1632, June 2017.

[29] G. Tao and P. V. Kokotović, Adaptive and Learning Systems for Signal Processing, Communications, and Control, John Wiley \& Sons, New York, USA, 1996. 